\title{
Induction of somatic embryos in cultures of Asparagus racemosus Willd: an endangered medicinally important plant
}

\author{
Juhi Chaudhary ${ }^{*}$ and Prem Kumar Dantu
}

\begin{abstract}
Background: Somatic embryogenesis is one of the most popular in vitro regeneration methods for mass micropropagation. In the present study, somatic embryogenesis via zygotic embryos was studied in Asparagus racemosus Willd. Since the callus quality plays an important role in plantlet development, therefore, compact embryogenic callus was selected for further embryogenesis.
\end{abstract}

Results: Somatic embryos were induced by zygotic embryos germinating on callus induction medium (MS media with $1.54 \mathrm{mg} \mathrm{L}^{-1}$ 2,4-D and $0.43 \mathrm{mg} \mathrm{L}^{-1}$ kinetin) in dark. Thereafter, the compact embryogenic callus differentiated up on MS media with $0.1 \mathrm{mg} \mathrm{L}^{-1} \mathrm{NAA}$ and $0.5 \mathrm{mg} \mathrm{L}^{-1}$ kinetin supplemented with various concentrations of ancymidol. An addition of $0.75 \mathrm{mg} \mathrm{L}^{-1}$ ancymidol resulted in significant enhancement of somatic embryo formation and no malformed embryos were observed. Scanning electron micrographs and thin sections confirmed the structures as somatic embryos. Furthermore, these embryos were transferred to the same medium supplemented with glutamine, casein hydrolysate, and 3\% sucrose for conversion into green shoots. These shoots could be multiplied in vitro using BAP-supplemented medium.

Conclusions: An effective method for conservation of an overexploited threatened medicinally important species Asparagus racemosus has been developed. This is the first report of the formation of somatic embryos from zygotic embryos in A. racemosus. Ancymidol in combination with kinetin and NAA was found to be most efficient for somatic embryo maturation and germination. The established protocol would certainly advance the efficient somatic embryo induction, maturation, and germination which could be utilized for large-scale propagation of Asparagus species.

Keywords: Asparagus racemosus, Shatavar, Somatic embryos, Zygotic embryos, Embryogenic callus, Ancymidol

\section{Introduction}

Asparagus racemosus Willd. (common name Shatavar; Asparagaceae) is an important medicinal plant native to the Indian subcontinent. The tuberous roots of $A$. racemosus are rich in the saponins, Shatavarin I to IV having rejuvenating and phytoestrogenic properties. These saponins are now extensively used in hormone replacement therapy instead of synthetic estrogens that are neither safe nor effective (Barrett-Connor, 1998). Roots of $A$. racemosus are also reported to have antioxidant,

\footnotetext{
* Correspondence: juhi.chaudhary@gmail.com

Plant Biotechnology Laboratory, Department of Botany, Dayalbagh Educational Institute (Deemed University), Dayalbagh, Agra, India
}

anti-ADH (Wiboonpun et al. 2004), and anti-amnesic activity (Ojha et al. 2010).

In view of the increasing world population to cross nine billion by 2050, indicating that the crop supplies must be doubled to meet the requirement in changing climatic conditions (Chaudhary et al. 2015; Chaudhary et al. 2018). A. racemosus roots are extensively collected from the wild causing mass destruction of the germplasm. This overexploitation has put considerable survival pressure on this plant making it endangered in the region of its natural existence (Kala et al. 2006; Chaudhary and Dantu, 2011). The plant is normally propagated through seeds and by splitting the cluster of roots. However, due to poor seed set and germination and low availability of crown roots, propagation of elite 
lines is too slow. For these reasons, commercial production of this crop has remained consistently low and not able to fulfill the high market demands. This problem could be offset by the rapid multiplication of A. racemosus through tissue culture. Adventitious regeneration from callus (Kar and Sen, 1985) and clonal propagation through axillary branching (Bopana and Saxena, 2008) have been reported earlier in A. racemosus. In vitro proliferation in this genus through somatic embryos has been reported for Asparagus species such as A. officinalis (Kohmura et al. 1994; Li and Wolyn, 1995) A. breslerianus (Mousavizadeh et al. 2017) through this process has been reported for a large number of other species such as Carica papaya L. (Anandan et al. 2012), Musa (Ma et al. 2012; Divakaran and Nair, 2011), and Cymbidium bicolor Lindl. (Mahendran and Bai, 2012). Somatic embryogenesis is the preferred method for mass proliferation because of the possibility of rapid scale-up through a bioreactor for direct plantation as in coffee (Ducos et al. 2010) or encapsulation and use as artificial seeds (Utomo et al. 2008). We have been working on developing appropriate propagation methods and agronomic practices for this plant (Chaudhary and Dantu, 2011). In this paper, we report a method for induction of embryogenic callus and differentiation of somatic embryos from zygotic embryos. These somatic embryos could be germinated to form shoots on a modified medium, which could then be multiplied through shoot proliferation for increasing their numbers. This is the first report for production of the somatic embryo using zygotic embryos for this plant and conservation of this species could be a noteworthy genetic resource for future asparagus breeding programs.

\section{Materials and methods}

\section{Plant material and medium}

Asparagus racemosus accession no. IC471921 was obtained from National Bureau of Plant Genetic Resources, New Delhi, and established in the Botanical Garden of the Institute. Embryos were dissected under aseptic conditions from berries sterilized in $70 \%$ ethanol followed by direct flaming.

MS (Murashige and Skoog, 1962) basal medium supplemented with 3\%(w/v) sucrose and $0.8 \%(w / v)$ agar was used for all experiments unless otherwise stated. Medium taken in suitable culture vials was sterilized at $121{ }^{\circ} \mathrm{C}$ and 15 Psi for $15 \mathrm{~min}$. For callus induction, young embryos were cultured on MS medium supplemented with various concentrations of either 2,4-D $(0,1.1,1.54$, or $2.2 \mathrm{mg} \mathrm{L}^{-1}$ ) alone or in combination with $0.43 \mathrm{mg} \mathrm{L}^{-1}$ kinetin. The callus from callus induction medium (CIM) was transferred to somatic embryo induction (SEI) medium. SEI medium was first standardized for the growth regulators NAA $\left(0.05,0.1 \mathrm{mg} \mathrm{L}^{-1}\right)$ and kinetin $\left(0.5,1.0 \mathrm{mg} \mathrm{L}^{-1}\right)$ and then for ancymadol $(0.5,0.75$, or 1.0 $\left.m g \mathrm{~L}^{-1}\right)$. Developed somatic embryos from the SEI medium were transferred for germination (somatic embryo germination, SEG medium) to MS with $0.1 \mathrm{mg}$ $\mathrm{L}^{-1}$ NAA, $0.5 \mathrm{mg} \mathrm{L}^{-1}$ kinetin, and $0.75 \mathrm{mg} \mathrm{L}^{-1}$ ancymidol supplemented with either (i) $600 \mathrm{mg} \mathrm{L}^{-1}$ glutamine and $400 \mathrm{mg} \mathrm{L}^{-1}$ casein hydrolysate, or (ii) $800 \mathrm{mg} \mathrm{L}^{-1}$ glutamine and $500 \mathrm{mg} \mathrm{L}^{-1}$ casein hydrolysate. These media contained either 3 or $5 \%$ sucrose. For shoot multiplication and elongation, germinating shoots were transferred to MS supplemented with BAP $(0,0.002,0.01,0.02,0.04$, $0.06,0.08$, and $\left.0.1 \mathrm{mg} \mathrm{L}^{-1}\right)$. To achieve shoot proliferation and cluster multiplication, healthy cultures were further subcultured to three concentrations of BAP $(0.04,0.06$, $0.08 \mathrm{mg} \mathrm{L}^{-1}$ ).

Cultures of zygotic embryos for callus induction were incubated either in dark or under $16 \mathrm{~h}$ photoperiod for the initial 4 weeks after which all cultures were maintained under $16 \mathrm{~h}$ photoperiod and $30 \mu \mathrm{E} \mathrm{m} \mathrm{m}^{-2} \mathrm{~s}^{-1}$ irradiance provided by cool white fluorescent tubes.

\section{Histology and SEM}

The elongated bipolar embryo-like structures were fixed in formalin:acetic acid:70\% ethanol (1:1:18) and dehydrated through a xylene-tertiary butyl alcohol series before gradual infiltration with xylene-paraffin wax and embedding in molten paraffin wax. The specimens were sectioned at $8 \mu \mathrm{m}$ (MICROM HM 340E microtome, Germany), stained with $1 \%$ hematoxylin and erythrosine and observed in a Nikon optical microscope E200 (Nikon, Japan), and photographed using Nikon Digital Sight.

For scanning electron microscopy (SEM), calli-bearing somatic embryos were fixed in $2.5 \%$ glutaraldehyde in $0.1 \mathrm{M}$ phosphate buffer, $\mathrm{pH} 7.4$ for $24 \mathrm{~h}$ at $4{ }^{\circ} \mathrm{C}$ (De Mason et al. 1989). After washing in the same buffer, the material was dehydrated in a graded ethanol series, critical point dried, and coated with a thin layer of gold. The processed material was scanned and photographed in a Leo 435 VP Scanning Electron Microscope at an acceleration voltage of $15-30 \mathrm{kV}$ at All India Institute of Medical Sciences, New Delhi.

\section{Statistical analysis}

Data for each experiment was recorded by counting the number of somatic embryos per culture and presented as mean \pm standard error (SE). Quantitative data were analyzed using one-way analysis of variance (ANOVA) and comparisons between the mean values of treatment were made by Duncan's multiple range test (DMRT) at 0.05 level of probability using SPSS 18.0.

\section{Results}

The simple sterilization procedure resulted in recovering $100 \%$ sterile cultures. Zygotic embryos cultured on 2,4- 
D alone did form callus but the presence of kinetin was absolutely necessary for the development of embryogenic callus (Table 1). MS culture media containing 0.43 $\mathrm{mg} \mathrm{L}^{-1}$ kinetin and $1.54 \mathrm{mg} \mathrm{L}^{-1}$ 2,4-D resulted in $74 \%$ cultures that formed creamish, hard, nodular, compact callus (compact embryogenic callus (CEC)), and also showed some globular (Fig. 1a) and bipolar embryos. The callus was regularly maintained on this medium for the continuous formation of somatic embryos.

Somatic embryo induction could be achieved on changing the auxin from 2,4-D to NAA, increasing kinetin concentration and addition of the growth retardant ancymidol to the CIM. An optimum concentration of NAA $\left(0.1 \mathrm{mg} \mathrm{L}^{-1}\right)$ and kinetin $\left(0.5 \mathrm{mg} \mathrm{L}^{-1}\right)$ resulted in 4.83 embryos per culture (Table 2). An addition of 0.75 $\mathrm{mg} \mathrm{L}^{-1}$ ancymidol to this medium increased the number of globular (14 per culture; Fig. 1b) embryos with $77 \%$ maturing into bipolar embryos (11 per culture; Fig. 1c) at the end of 6 weeks. The globular embryos had a shining smooth surface while the bipolar embryos appeared as elongated structures (Fig. 1b, c).

The SEI medium supplemented with glutamine $(600$ and $800 \mathrm{mg} \mathrm{L}^{-1}$ ), casein hydrolysate (400 and $500 \mathrm{mg}$ $\mathrm{L}^{-1}$ ), and sucrose (3 or $5 \%$ ) promoted germination of somatic embryos (Fig. 1d). Glutamine at $600 \mathrm{mg} \mathrm{L}^{-1}$ and casein hydrolysate at $400 \mathrm{mg} \mathrm{L}^{-1}$ in the presence of $3 \%$ sucrose supported germination in almost $65 \%$ of cultures within 2 weeks of transfer.

Furthermore, histological and SEM studies confirmed the structure of somatic embryos in the present work. A longitudinal section of the bipolar embryo showed a broad dome-like coleoptile enclosing the scutellum with a distinct narrow radicular end (Fig. 2a). SEM revealed that the globular embryos that were spherical and smooth surfaced (Fig. 2b) while the elongated bipolar embryos had an outer mesh-like epidermis (Fig. 2c)

Shoot multiplication was carried out on MS media supplemented with BAP. At higher BAP concentration, there was a steady increase in the multiple shoot buds

Table 1 Effect of 2,4-D and kinetin concentrations on callus induction on zygotic embryo cultures.

\begin{tabular}{|c|c|c|c|}
\hline \multirow[t]{2}{*}{ S. no. } & \multicolumn{2}{|c|}{ Growth regulators $\left(\mathrm{mg} \mathrm{L}^{-1}\right)$} & \multirow{2}{*}{$\begin{array}{l}\% \text { of explants* } \\
\text { producing CEC }\end{array}$} \\
\hline & $2,4-D$ & $\mathrm{Kn}$ & \\
\hline 1. & 0 & 0 & 4 \\
\hline 2. & 1.1 & 0 & 15 \\
\hline 3. & 1.5 & 0 & 45.2 \\
\hline 4. & 2.2 & 0 & 33.9 \\
\hline 5. & 1.1 & 0.43 & 54.4 \\
\hline 6. & 1.5 & 0.43 & 73.5 \\
\hline 7. & 2.2 & 0.43 & 61.7 \\
\hline
\end{tabular}

*Twenty-four replicates per treatment, repeated thrice

Only cultures incubated in dark produced compact embryogenic callus (CEC)

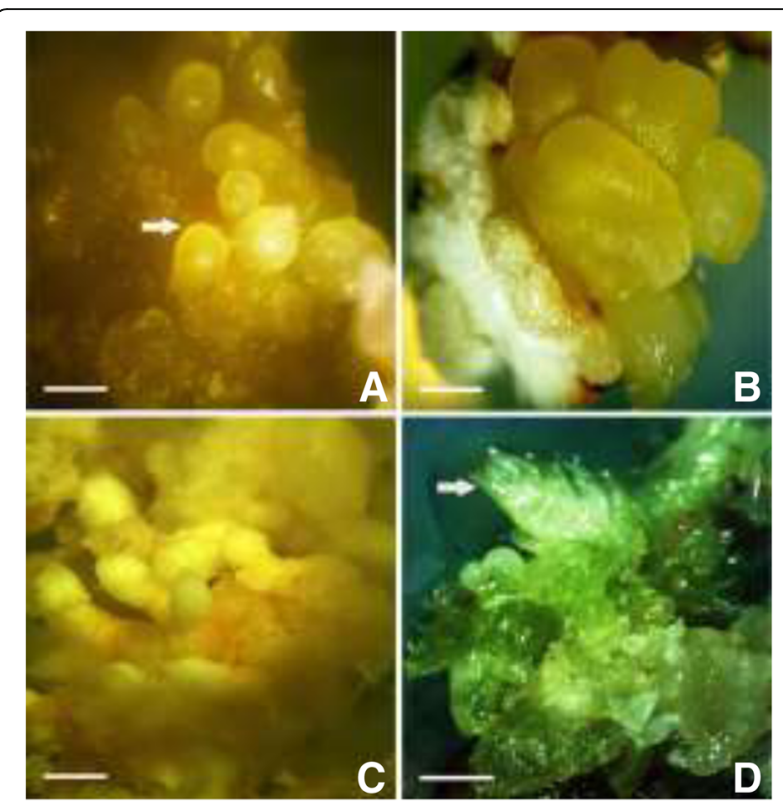

Fig. 1 Induction of somatic embryogenesis in Asparagus racemosus from zygotic embryos. a Initiation of globular embryos (arrow marked) from embryogenic callus on CIM (bar 0.09 mm). b Globular embryo differentiation after 30 days of transfer to SEI medium. Note the smooth shining surface of the globular embryos (bar $0.05 \mathrm{~mm}$ ). c Bipolar embryo structures developing from globular embryos 30 days after subculture to fresh SEI medium (bar $0.15 \mathrm{~mm}$ ). d Germinating multiple somatic embryos (arrow marked) 14 days after transfer to SEG medium (bar $0.135 \mathrm{~mm}$ )

but shoots were shorter. Three concentrations of BAP (0.04, 0.06, and $0.08 \mathrm{mg} \mathrm{L}^{-1}$ ) demonstrated high shoot numbers with no stunted shoots. Maximum number of shoots (15.87) per cluster was obtained on MS supplemented with $0.08 \mathrm{mg} \mathrm{L}^{-1}$ BAP with an average length of $2.93 \mathrm{~cm}$ (Table 3). Moreover, the shoots were observed thick and healthy in this medium.

\section{Discussion}

In vitro somatic embryogenesis is one of the most useful biotechnological tools used in plant breeding, propagation, and conservation approaches. There are several

Table 2 Effect of NAA and kinetin concentration on somatic embryo induction from zygotic embryos

\begin{tabular}{lll}
\hline S. no. & $\begin{array}{l}\text { Growth regulators } \\
\left(\mathrm{mg} \mathrm{L}^{-1}\right)\end{array}$ & $\begin{array}{l}\text { No. of somatic embryos } \\
\text { per culture }\end{array}$ \\
\hline 1. & $0.05 \mathrm{NAA}+0.5 \mathrm{KN}$ & $2.94 \pm 0.76^{\mathrm{a}}$ \\
2. & $0.05 \mathrm{NAA}+1.0 \mathrm{KN}$ & $3.88 \pm 0.64^{\mathrm{a}}$ \\
3. & $0.10 \mathrm{NAA}+0.5 \mathrm{KN}$ & $4.83 \pm 0.39^{\mathrm{b}}$ \\
4. & $0.10 \mathrm{NAA}+1.0 \mathrm{KN}$ & $2.71 \pm 0.78^{\mathrm{a}}$ \\
\hline
\end{tabular}

Values represent mean $\pm \mathrm{SE}$

*Fifteen replicates per treatment, repeated thrice

One-way ANOVA with Duncan's multiple range test was applied

Data in columns followed by different letter (superscript) significantly different at $0.05 \%$ level 

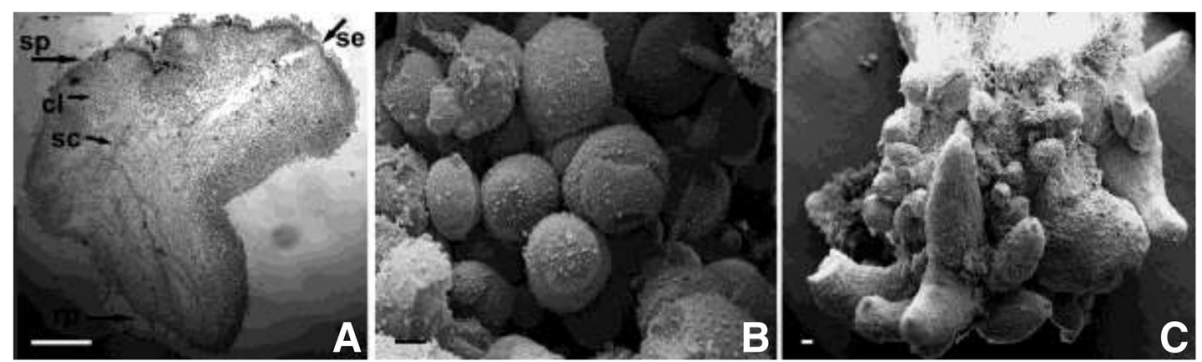

Fig. 2 Histology and SEM of somatic embryos. a L.S. of somatic embryo revealing a primary somatic embryo (pe) with shoot pole (sp) and root pole (rp). A secondary embryo (se) is arising from the body of the primary embryo. Note the coleoptile (cp) and scutellum (sc). (bar $0.42 \mathrm{~mm}$ ). b, c SEM of somatic embryos. b globular embryos; note the distinct dome-like structures with smooth epidermal surface (c) bipolar embryo. Note the characteristic mesh-like epidermal surface (bar $30 \mu \mathrm{m}, 200 \mu \mathrm{m}$, respectively)

factors which affect somatic embryogenesis and regeneration, for example, explant type and culture media. Somatic embryo formation has been extensively studied in $A$. officinalis using various explants (Li and Wolyn, 1995; Levi and Sink, 1992; Dupire et al. 1999). Zygotic embryos have been utilized in several plant species such as Quercus suber (Testillano et al. 2018) and peach palm (Steinmacher et al. 2016). The responsiveness of zygotic embryos to somatic embryo formation is being reported here for the first time for any species of Asparagus.

The growth hormone plays a critical role in embryo induction, maturation, and germination. NAA is considered to be a milder auxin and has often proved to be better than 2,4-D in maturing of somatic embryos as in Centella (Martin, 2004). Therefore, 2,4-D was used in the CEI medium while NAA was studied in SEI medium. Furthermore, inclusion of ancymidol in SEI medium inhibited callus proliferation and promoted globular and bipolar embryo differentiation only in the compact and nodular callus. Ancymidol is a known inhibitor of gibberellic acid biosynthesis and by promoting the accumulation of storage protein that improves somatic embryo maturation (Li and Wolyn, 1995). During the progress of globular embryos into bipolar structures, the outer epidermal cells elongate giving a mesh-like appearance. Similar changes in epidermal cells were observed in the SEM of somatic

Table 3 Effect of BAP on in vitro shoot cluster multiplication in Asparagus racemosus

\begin{tabular}{llll}
\hline S. no. & $\begin{array}{l}\text { BAP concentration } \\
\left(\mathrm{mg} \mathrm{L}^{-1}\right)\end{array}$ & Mean no. of shoots* & $\begin{array}{l}\text { Mean length of } \\
\text { shoots }(\mathrm{cm})^{*}\end{array}$ \\
\hline 1. & 0.04 & $11.36 \pm 0.51^{\mathrm{a}}$ & $4.48 \pm 0.28^{\mathrm{a}}$ \\
2. & 0.06 & $12.27 \pm 0.65^{\mathrm{ab}}$ & $3.88 \pm 0.29^{\mathrm{a}}$ \\
3. & 0.08 & $15.87 \pm 0.56^{\mathrm{b}}$ & $2.93 \pm 0.24^{\mathrm{b}}$ \\
\hline
\end{tabular}

Values represent mean $\pm \mathrm{SE}$

*Twenty replicates per treatment, repeated thrice. One-way ANOVA with Duncan's multiple range test was applied

Data in columns followed by different letter (superscript) significantly different at $0.05 \%$ level embryos of Musa species (Pan et al. 2011). Inclusion of glutamine and casein hydrolysate in SEG medium improved both maturation and germination of the somatic embryos in the present study as have been shown in earlier studies in A. officinalis (Li and Wolyn, 1995) and chickpea (Patil et al. 2009). Varying sucrose concentrations affected somatic embryo formation, their maturation, and germination in A. officinalis (Levi and Sink, 1992). In A. racemosus, ancymidol was noticed to enhance somatic embryogenesis only in combination with a certain level of a carbon source and/or osmoticum in the medium.

In the present study, the growth hormone BAP was tested for the germination of the somatic embryo. The medium supplemented with $0.08 \mathrm{mg} \mathrm{L}^{-1}$ BAP was observed to be best for producing about 16 shoots per cluster. Kar and Sen (1985) has demonstrated the multiplication of shoots in $A$. racemosus derived from callus cultures on a medium containing BAP $\left(1 \mathrm{mg} \mathrm{L}^{-1}\right)$ and IAA $\left(0.1 \mathrm{mg} \mathrm{L}^{-1}\right)$.

\section{Conclusion}

This is the first report describing in vitro somatic embryo formation in A. racemosus. Ancymidol was found to be the key plant growth regulator for multiplication and maturation during somatic embryogenesis since along with NAA and kinetin. It also reduced the formation of malformed somatic embryos and facilitated further embryo maturation and germination. The established protocol in this study will be valuable for somatic embryogenesis induction and maintenance which could be applied for mass propagation and germplasm conservation of this species.

\section{Abbreviations}

Ancymidol: a-cyclopropyl-a (4-methoxyphenyl)-5-pyrimidine methanol; CIM: Callus induction medium; MS: Murashige and Skoog; NAA: anaphthaleneacetic acid; SEl: Somatic embryo induction; SEG: Somatic embryo germination; SEM: Scanning electron microscopy; 2,4-D: 2,4dichlorophenoxyacetic acid 


\section{Acknowledgements}

The authors gratefully acknowledge the Director of the Institute for providing the facilities to carry out the work. Director, NBPGR, New Delhi, is duly acknowledged for providing the plant material. All India Institute of Medical Sciences, New Delhi, is acknowledged for providing SEM facility.

\section{Authors' contributions}

PKD and JC conceived and planned the study. JC and PKD contributed to drafting the manuscript. JC performed the data analysis and interpretation. Both authors read and approved the final manuscript.

\section{Funding}

Funding by University Grants Commission, New Delhi, through a major project vide letter no. F.32-382/2006 (SR) is acknowledged by PKD and JC.

\section{Availability of data and materials}

Not applicable

Ethics approval and consent to participate

Not applicable

\section{Consent for publication}

Not applicable

\section{Competing interests}

The authors declare that they have no competing interests.

Received: 17 March 2019 Accepted: 2 July 2019

Published online: 18 July 2019

\section{References}

Anandan R, Sudhakar D, Balasubramanian P, Gutierrez-Mora A (2012) In vitro somatic embryogenesis from suspension cultures of Carica papaya $\mathrm{L}$. Sci Hortic 136:43-49

Barrett-Connor E (1998) Hormone replacement therapy, heart disease, and other considerations. Ann Rev Pub Health 19:55-72

Bopana N, Saxena S (2008) In vitro propagation of a high value medicinal plant: Asparagus racemosus Willd. In Vitro Cell Dev Biol 44:525-532

Chaudhary J, Dantu PK (2011) Collection, establishment, acclimatization and quantification of Shatavarin IV in the medicinally important plant-Asparagus racemosus Willd. In: Chemistry of Phytopotentials: Health, Energy and Environmental Perspectives, 1st edn. Springer, Heidelberg Dordrecht London New York, pp 83-86

Chaudhary J, Patil GB, Sonah H, Deshmukh RK, Vuong TD, Valliyodlan B, Nguyen HT (2015) Expanding omics resources for improvement of soybean seed composition traits. Front Plant Sci 6:1021

Chaudhary J, Shivaraj SM, Khatri P, Ye H, Zhou L, Klepadlo M, Dhakate P, Kumawat G, Patil G, Sonah H, Ratnaparkhe M, Deshmukh R, Nguyen HT (2018) Approaches, Applicability, and Challenges for Development of Climate-Smart Soybean. In: Kole C (ed) Genomic Designing of Climate-Smart Oilseed Crops. Springer, Cham, pp 1-74

De Mason DA, Sekhar KNC, Harris M (1989) Endosperm development in the date palm (Phoenix dactylifera) (Arecaceae). Am J Bot 6:1255-1265

Divakaran SP, Nair AS (2011) Somatic embryogenesis from bract cultures in diploid Musa acuminata cultivars from South India. Sci Hortic 131:99-102

Ducos J-P, Terrier B, Courtois D (2010) Disposable bioreactors for plant micropropagation and mass plant cell culture. Adv Biochem Eng/Biotech 115:89-115

Dupire L, De'cout E, Vasseur J, Delbriel B (1999) Histological and 2-D protein patterns comparisons between a wild type and a somatic embryogenic mutant of Asparagus officinalis L. Plant Sci 147:9-17

Kala CP, Dhyani PP, Sajwan BS (2006) Developing the medicinal plants sector in northern India: challenges and opportunities. J Ethnobiol Ethnomed 2:32

Kar DK, Sen S (1985) Propagation of Asparagus racemosus through tissue culture. Plant Cell Tissue Organ Cult 5:89-95

Kohmura H, Chokyu S, Harada T (1994) An effective micropropagation system using embryogenic calli induced from bud clusters in Asparagus officinalis $\mathrm{L}$. J Japan Soc Hort Sci 63:51-59

Levi A, Sink KC (1992) Asparagus somatic embryos: production in suspension culture and conversion to plantlets on solidified medium as influenced by carbohydrate regime. Plant Cell Tissue Organ Cult 31:115-122
Li B, Wolyn DJ (1995) The effects of ancymidol, abscisic acid, uniconazole and paclobutrazol on somatic embryogenesis of Asparagus. Plant Cell Rep 14:529-534

Ma L, Xie L, Lin G, Jiang S, Chen H, Li H, Takáč T, Šamaj J, Xu C (2012) Histological changes and differences in activities of some antioxidant enzymes and hydrogen peroxide content during somatic embryogenesis of Musa AAA cV. Yueyoukang 1. Sci Hortic 144:87-92

Mahendran G, Bai VN (2012) Direct somatic embryogenesis and plant regeneration from seed derived protocorms of Cymbidium bicolor Lindl. Sci Hortic 135:40-44

Martin KP (2004) Plant regeneration through somatic embryogenesis in medicinally important Centella asiatica L. In Vitro Cell Dev Biol 40:586-591

Mousavizadeh SJ, Mashayekhi K, Hassandokht MR (2017) Indirect somatic embryogenesis on rare octoploid Asparagus breslerianus plants. Sci Hortic 226:184-190

Murashige T, Skoog F (1962) A revised medium for the rapid growth and bioassays with tobacco tissue cultures. Physiol Plant 15:473-497

Ojha R, Sahu AN, Muruganandam AV, Singh GK, Krishnamurthy S (2010) Asparagus racemosus enhances memory and protects against amnesia in rodent models. Brain and Cognition 74:1-9

Pan X, Yang X, Lin G, Zou R, Chena H, Šamaj J, Chunxiang X (2011) Ultrastructural changes and the distribution of arabinogalactan proteins during somatic embryogenesis of banana (Musa spp. AAA cv. 'Yueyoukang 1'). Physiol Plant 142:372-389

Patil G, Patel R, Jaat R, Pattanayak A, Jain P, Srinivasan R (2009) Glutamine improves shoot morphogenesis in chickpea (Cicer arietinum L.). Acta Physiol Plant 31:1077-1084

Steinmacher DA, Heringer AS, Jimenez VM, Quoirin MGG, Guerra MP (2016) Somatic embryogenesis in Peach-Palm (Bactris gasipaes) using different explant sources. In Vitro Embryogenesis in Higher Plants:279-288

Testillano PS, Pintos B, Gomez-Garay A, Risueno MC (2018) Stress-induced microspore embryogenesis by anther culture of Quercus suber L. Step Wise Protocols for Somatic Embryogenesis of Important Woody Plants:93-105

Utomo HS, Wenefrida I, Meche MM, Nash JL (2008) Synthetic seed as a potential direct delivery system of mass-produced somatic embryos in the coastal marsh plant smooth cordgrass (Spartina alterniflora). Plant Cell Tissue Organ Cult 92:28-291

Wiboonpun NP, Phuwapraisirisan S, Tip-Pyang S (2004) Identification of antioxidant compound from Asparagus racemosus. Phytother Res 18:771-773

\section{Publisher's Note}

Springer Nature remains neutral with regard to jurisdictional claims in published maps and institutional affiliations.

\section{Submit your manuscript to a SpringerOpen ${ }^{\circ}$ journal and benefit from:}

- Convenient online submission

- Rigorous peer review

- Open access: articles freely available online

High visibility within the field

- Retaining the copyright to your article

Submit your next manuscript at $\boldsymbol{\nabla}$ springeropen.com 